\title{
Effectiveness of stress management in patients undergoing transrectal ultrasound-guided biopsy of the prostate
}

This article was published in the following Dove Press journal:

Patient Preference and Adherence

II February 2016

Number of times this article has been viewed

\author{
Li-Pin Chiu ${ }^{1,2}$ \\ Heng-Hsin Tung ${ }^{3}$ \\ Kuan-Chia Lin ${ }^{3}$ \\ Yu-Wei Lai ${ }^{1,4}$ \\ Yi-Chun Chiu',4 \\ Saint Shiou-Sheng Chen ${ }^{1,4}$ \\ Allen W Chiu',4 \\ 'Division of Urology, Taipei City \\ Hospital, ${ }^{2}$ University of Taipei, General \\ Education Center, ${ }^{3}$ School of Nursing, \\ Department of Care Management, \\ National Taipei University of Nursing \\ and Health Science, ${ }^{4}$ Department \\ of Urology, National Yang-Ming \\ University School of Medicine, \\ Taipei, Taiwan, Republic of China
}

Background: To assess the utilization of stress management in relieving anxiety and pain among patients who undergo transrectal ultrasound (TRUS)-guided biopsy of the prostate.

Methods: Eighty-two patients admitted to a community hospital for a TRUS biopsy of the prostate participated in this case-controlled study. They were divided into an experimental group that was provided with stress management and a control group that received only routine nursing care. Stress management included music therapy and one-on-one simulation education. Before and after the TRUS biopsy, the patients' state-anxiety inventory score, pain visual analogue scale (VAS), respiratory rate, heart rate, and blood pressure were obtained.

Results: There were no differences in baseline and disease characteristics between the two groups. The VAS in both groups increased after the TRUS biopsy, but the difference in pre- and postbiopsy VAS scores was significantly lower in the experimental group $(P=0.03)$. Patients in both groups experienced mild anxiety before and after the biopsy, but those in the experimental group displayed a significantly greater decrease in postbiopsy state-anxiety inventory score compared to the control group $(P=0.02)$.

Conclusion: Stress management can alleviate anxiety and pain in patients who received a TRUS biopsy of the prostate under local anesthesia.

Keywords: anxiety, pain, stress management, transrectal ultrasound-guided biopsy of the prostate

\section{Introduction}

Based on the consensus of the American and Taiwan Urological Associations on the diagnosis and treatment of prostate cancer, if the serum prostate-specific antigen (PSA) level exceeds $4 \mathrm{ng} / \mathrm{mL}$, transrectal ultrasound (TRUS)-guided biopsy should be recommended to obtain prostate tissue for pathologic diagnosis. However, $\sim 20 \%$ of patients experienced high stress and anxious moods when undergoing the TRUS biopsy. ${ }^{1}$ Some researchers note that this procedure does not require anesthesia, although $\sim 70 \%$ of patients believe that the pain will be intolerable without the use of anesthesia or sedatives. ${ }^{2}$

There are two causes of discomfort during TRUS biopsy. One originates from the movement of the ultrasound probe inside the rectum, and the other is the pain induced by the insertion of the biopsy needle into the prostate. ${ }^{3}$ Moreover, anxiety and anal tension will also influence the pain tolerance of patients. ${ }^{4}$ Previous studies have focused on whether pain relievers, local anesthesia, or even sedatives should be given to patients before or during the procedure.

Currently, there are many studies regarding music therapy and presurgical health education to relieve the pain and anxiety of patients..$^{5-9}$ However, most simulated education

\footnotetext{
Correspondence: Saint Shiou-Sheng Chen Division of Urology, Taipei City Hospital, Renai Branch, National YangMing University, School of Medicine, \#I0, Renai Street, Section 4, Taipei 106 Taiwan, Republic of China

Tel +886227093600 ext 3615

Fax +886227045064

Email eric.yoyo@msa.hinet.net
} (c) 1 (i) 2016 Chiu et al. This work is published and licensed by Dove Medical Press Limited. The full terms of this license are available at https:///www.dovepress.com/terms.php hereby accept the Terms. Non-commercial uses of the work are permitted without any further permission from Dove Medical Press Limited, provided the work is properly attributed. For permission for commercial use of this work, please see paragraphs 4.2 and 5 of our Terms (https://www.dovepress.com/terms.php). 
is being implemented in educational research and less in clinical application. Tsivian et al and Yeo et al reported that pain increased in patients after TRUS biopsy or cystoscopy, but a significantly lesser increase was noted in the music therapy group. ${ }^{5,6}$ Doering et al showed no significant effects of videotape preparation before surgery on postoperative pain, ${ }^{7}$ whereas LaMontagne et al reported cognitive behavioral intervention with a videotape containing information on coping, which was effective in reducing postoperative pain. ${ }^{8}$ Preoperative nursing education was associated with a significant reduction in postoperative pain in the study by Hsiang et al. ${ }^{9}$ In literature review, there are few studies on the effect of combined simulation education and musical therapy to reduce the pain and anxiety of patients' post-TRUS biopsy.

This study was conducted to evaluate the effect of stress management of combined music therapy and one-on-one simulation education on reducing anxiety and pain level in patients undergoing TRUS biopsy of the prostate under local anesthesia.

\section{Methods}

This is a case-control study that recruited patients from Taipei City Hospital, Renai branch in northern Taiwan. Based on the Cohen's rule, the effect size $(d)$ was set as 0.3 , with a statistical power at 0.80 . Eighty-two patients admitted for TRUS biopsy of the prostate due to elevated PSA ( $>4 \mathrm{ng} / \mathrm{dL})$ were randomly allocated into the experimental and the control groups. Data from the control group were collected in 1 week, while that for the experimental group was obtained in the following week. The institutional review board of Taipei City Hospital approved the study. All of the patients provided written informed consent to participate in the study.

The patients' basic data, including age, serum PSA, marital status, and number of biopsies, were obtained. At preand postbiopsy, their physiologic indicators (eg, heart rate, respiratory rate, and blood pressure), pain visual analogue scale (VAS) scores, and state-anxiety inventory (SAI) scores were also collected by nursing practitioners of urology. The major variables were VAS and SAI scores. All patients were given intravenous pethidine ( $25 \mathrm{mg}$ ), and lidocaine jelly was applied on the anus before initiating the procedure.

The VAS scores ranged from 0 to 10: 10 meaning extreme severity and 0 meaning no symptoms. ${ }^{10}$ The SAI score, an indicator of the anxiety level of patients under certain stressful situations, had 20 questions and was scored using a 4-point Likert scale. The patients responded in four levels: 1 - "not anxious at all", 2 -“somewhat anxious", 3 - "very anxious", and 4 - "extremely anxious". A score of 1-4 was given per question for a total score of 20-80. A lower score indicated a lower anxiety level such that a score of 20-39 indicated mild anxiety, 40-59 indicated intermediate anxiety, and 60-80 indicated severe anxiety.

\section{Stress management}

Music for relaxing therapy should include some characteristics such as simple, repeated, and elegant rhythm, low pitch and $\sim 60-80$ pulses/min. ${ }^{11,12}$ Therefore, we used "Twilight's Embrace" by Kevin Kern from the album Summer Daydreams. Volume was controlled by the patient based on personal comfort as the music played through headphones. The one-on-one simulation education was conveyed by the researcher to the patients by simultaneous explanation, which included the preparation before the biopsy, the procedure itself, and the cautions and possible complications after. The simulation education process took approximately 20 minutes, which can make patients familiar with the environment where biopsy was performed and the detailed process of biopsy.

All data analyses were performed using the SPSS18.0 Statistical Software (Windows Version 18.0, SPSS Inc., Chicago, IL, USA). The variables studied included descriptive statistics and inferential statistics (chi-square test, independent $t$-test, paired $t$-test, and generalized estimating equation). Generalized estimating equation is a linear model to evaluate the linear relation between dependent and independent variables and can increase the accuracy for analysis of independent samples.

\section{Results}

The general information for all the patients revealed no significant differences for all of the parameters (Tables 1 and 2). The prebiopsy baseline VAS score was higher in the experimental group than in the control group (Table 3 ). However, the pre- and postbiopsy VAS scores in the experimental and control groups (Table 3 ) revealed that after accounting for cross-interaction, the postbiopsy VAS score significantly decreased by 1.63 with intervention measures compared to those without intervention measures.

Comparing the pre- and postbiopsy SAI scores between the experimental and the control groups (Table 3) using independent sample $t$-test, there was no statistical significance between the prebiopsy SAI score of both groups. In contrast, the postbiopsy SAI score of both groups was significantly different. The postbiopsy SAI score of the experimental group was significantly lower than that of the control group. The decrease in score of the experimental group was significantly higher than the reduction in the control group.

After accounting for cross-interaction and compared to the prebiopsy SAI score in the postbiopsy, SAI score 
Table I General information of patients participating in the stress management study

\begin{tabular}{|c|c|c|c|c|}
\hline Variables & $\begin{array}{l}\text { Control group } \\
n=4 I, n(\%)\end{array}$ & $\begin{array}{l}\text { Experimental group } \\
n=41, n(\%)\end{array}$ & $\chi^{2 / t}$ & $P$-value \\
\hline \multicolumn{5}{|l|}{ Marital status } \\
\hline Unmarried & I (2.4) & $3(7.3)$ & $1.229^{a}$ & 0.805 \\
\hline Married & $39(95.1)$ & $37(90.2)$ & & \\
\hline Divorced & I (2.4) & I (2.4) & & \\
\hline \multicolumn{5}{|l|}{ Listened to music } \\
\hline No & $20(48.8)$ & $15(36.6)$ & 1.246 & 0.264 \\
\hline Yes & $2 \mid(5 \mid .2)$ & $26(63.4)$ & & \\
\hline \multicolumn{5}{|l|}{ Music genre } \\
\hline Light music & $8(38.1)$ & $6(23.1)$ & $3.873^{\mathrm{a}}$ & 0.882 \\
\hline Classical & $2(9.5)$ & $5(19.2)$ & & \\
\hline Pop (Western) & $\mathrm{I}(4.8)$ & $\mathrm{I}(3.8)$ & & \\
\hline Pop (Mandarin) & I (4.8) & I (3.8) & & \\
\hline Pop (Taiwanese) & $2(9.5)$ & $2(7.7)$ & & \\
\hline Oldie (Mandarin) & $0(0)$ & $2(7.7)$ & & \\
\hline Oldie (Taiwanese) & $3(14.3)$ & $5(19.2)$ & & \\
\hline Other & $4(19)$ & $4(15.4)$ & & \\
\hline \multicolumn{5}{|l|}{ Exercise } \\
\hline No & $12(29.3)$ & $9(22)$ & 0.576 & 0.448 \\
\hline Yes & $29(70.7)$ & $32(78)$ & & \\
\hline \multicolumn{5}{|l|}{ Accompanied } \\
\hline Self & $9(22)$ & $13(3 \mid .7)$ & $3.773^{\mathrm{a}}$ & 0.279 \\
\hline Spouse & $26(63.4)$ & I8 (43.9) & & \\
\hline Children & $3(7.3)$ & $7(17.1)$ & & \\
\hline Other & $3(7.3)$ & $3(7.3)$ & & \\
\hline \multicolumn{5}{|l|}{ Caregiver } \\
\hline Self & $8(19.5)$ & I8 (43.9) & $5.909^{a}$ & 0.091 \\
\hline Spouse & $27(65.9)$ & $20(48.8)$ & & \\
\hline Children & $4(9.8)$ & $2(4.9)$ & & \\
\hline Other & $2(4.9)$ & I (2.4) & & \\
\hline \multicolumn{5}{|l|}{ Comorbidity } \\
\hline No & $26(63.4)$ & $33(80.5)$ & 2.961 & 0.085 \\
\hline Yes & $15(36.6)$ & $8(19.5)$ & & \\
\hline
\end{tabular}

Note: 'Fisher's exact test.

significantly decreased by 3.56 with intervention measures (Table 4), suggesting that these intervention measures were effective. Similarly, after accounting for cross-interaction and compared to the prebiopsy value, the postbiopsy breathing rate decreased by 0.66 in the experimental group but was not statistically significant (Table 4). The postbiopsy heart rate and systolic blood pressure in the experimental group were also lower than the prebiopsy values by 0.44 and 8.73 , respectively, but neither were statistically significant (Table 4).

Table 2 General information of all the subjects and in the two groups

\begin{tabular}{|c|c|c|c|c|c|}
\hline \multirow[t]{2}{*}{ Variables } & \multirow{2}{*}{$\frac{\text { Control group }(n=4 I)}{M \pm S D(\max , \min )}$} & \multirow{2}{*}{$\begin{array}{l}\text { Experimental group }(n=4 I) \\
M \pm S D(\max , \min )\end{array}$} & \multirow{2}{*}{$\frac{\text { Total }(n=82)}{M \pm S D(\max , \min )}$} & \multirow[t]{2}{*}{$t$} & \multirow[t]{2}{*}{$P$-value } \\
\hline & & & & & \\
\hline \multirow[t]{2}{*}{ Age (years) } & $71.9 \pm 9.11$ & $72.07 \pm 9.51$ & $71.99 \pm 9.25$ & -0.083 & 0.934 \\
\hline & $(87,52)$ & $(90,47)$ & $(90,47)$ & & \\
\hline PSA & $22.08 \pm 59.05$ & $10.28 \pm 8.26$ & $16.18 \pm 42.32$ & 1.267 & 0.212 \\
\hline (ng/dL) & $(36.6,4.07)$ & $(35.57,3.5)$ & $(36.6,3.5)$ & & \\
\hline Prostate & $50.8 \pm 21.75$ & $59.17 \pm 26.11$ & $54.98 \pm 24.25$ & -1.577 & 0.119 \\
\hline$\left(\mathrm{cm}^{3}\right)$ & $(98.7,4.5)$ & $(138,21.1)$ & $(138,4.5)$ & & \\
\hline Operation time & $7.39 \pm 1.79$ & $7.29 \pm 1.49$ & $7.34 \pm 1.63$ & 0.269 & 0.789 \\
\hline (minutes) & $(14,4)$ & $(12,5)$ & $(14,4)$ & & \\
\hline Music time & $0 \pm 0$ & $15.17 \pm 3.35$ & & & \\
\hline (minutes) & $(0,0)$ & $(25,10)$ & & & \\
\hline \multirow[t]{2}{*}{ Number of biopsies } & $10.54 \pm 1.03$ & $10.29 \pm 0.72$ & $|0.4| \pm 0.89$ & 1.248 & 0.216 \\
\hline & $(13,8)$ & $(12,10)$ & $(13,8)$ & & \\
\hline
\end{tabular}

Abbreviations: M, mean; SD, standard deviation; max, maximum; min, minimum; PSA, prostate-specific antigen. 
Table 3 Comparisons between the experimental and control group, pre- and posttest

\begin{tabular}{|c|c|c|c|c|c|c|}
\hline \multirow[t]{2}{*}{ Parameters } & $\begin{array}{l}\text { Control group } \\
(n=4 I)\end{array}$ & \multirow[t]{2}{*}{$P$-value } & \multirow{2}{*}{$\begin{array}{l}\text { Experimental group } \\
(n=4 I) \\
(M \pm S D)\end{array}$} & \multirow[t]{2}{*}{$P$-value } & \multirow{2}{*}{$\begin{array}{l}\text { All samples } \\
(n=82) \\
(M \pm S D)\end{array}$} & \multirow[t]{2}{*}{$P$-value } \\
\hline & $(\mathbf{M} \pm \mathbf{S D})$ & & & & & \\
\hline \multicolumn{7}{|l|}{ Pain score } \\
\hline Pretest & $0.46 \pm 0.8 \mathrm{I}$ & & $1.17 \pm 1.2$ & & $0.82 \pm 1.08$ & $0.002^{\mathrm{b}, * *}$ \\
\hline Posttest & $3.4 I \pm 2.55$ & & $2.49 \pm 2.46$ & & $2.95 \pm 2.53$ & $0.098^{b}$ \\
\hline Changes & $2.95 \pm 2.49$ & $0.000^{\mathrm{a}, * * *}$ & $1.32 \pm 2.56$ & $0.002^{\mathrm{a}, * *}$ & $2.13 \pm 2.64$ & $0.004^{\mathrm{b}, * *}$ \\
\hline \multicolumn{7}{|c|}{ Systolic pressure } \\
\hline Pretest & $|33.88 \pm| 6.07$ & & $|34.7| \pm \mid 6.39$ & & $134.29 \pm 16.13$ & $0.818^{b}$ \\
\hline Posttest & $153.39 \pm 22.58$ & & $145.49 \pm 26.29$ & & $\mid 49.44 \pm 24.67$ & $0.148^{b}$ \\
\hline Changes & $|9.5| \pm 22.98$ & $0.000^{\mathrm{a}, * * *}$ & $10.78 \pm 30.05$ & $0.027^{\mathrm{a}, *}$ & $15.15 \pm 26.95$ & $0.143^{b}$ \\
\hline \multicolumn{7}{|c|}{ Diastolic pressure } \\
\hline Pretest & $79.05 \pm 10.25$ & & $80.17 \pm 12.52$ & & $79.61 \pm 11.39$ & $0.658^{b}$ \\
\hline Posttest & $98.44 \pm 19.48$ & & $90.51 \pm 18.07$ & & $94.48 \pm 19.10$ & $0.060^{b}$ \\
\hline Changes & $19.39 \pm 20.34$ & $0.000^{\mathrm{a}, * * *}$ & $10.34 \pm 19.72$ & $0.002^{\mathrm{a}, * *}$ & $14.87 \pm 20.42$ & $0.044^{\mathrm{b}, *}$ \\
\hline \multicolumn{7}{|l|}{ Heart rate } \\
\hline Pretest & $78.93 \pm 8.9$ & & $74.78 \pm 12.34$ & & $76.85 \pm 10.89$ & $0.085^{b}$ \\
\hline Posttest & $73.93 \pm 13.39$ & & $69.34 \pm 15.18$ & & $71.63 \pm|4.4|$ & $0.15 \mathrm{I}^{\mathrm{b}}$ \\
\hline Changes & $-5.00 \pm 12.1$ & $0.012^{\mathrm{a}, *}$ & $-5.44 \pm 17.64$ & $0.055^{\mathrm{a}}$ & $-5.22 \pm 15.04$ & $0.896^{b}$ \\
\hline \multicolumn{7}{|l|}{ Breathing } \\
\hline Pretest & $18.98 \pm 1.52$ & & $18.88 \pm 1.72$ & & $18.93 \pm 1.62$ & $0.787^{b}$ \\
\hline Posttest & $19.59 \pm 5.07$ & & $18.83 \pm 4.16$ & & $19.21 \pm 4.63$ & $0.463^{b}$ \\
\hline Changes & $0.6 I \pm 5.24$ & $0.46 \mathrm{I}^{\mathrm{a}}$ & $-0.05 \pm 4.43$ & $0.944^{\mathrm{a}}$ & $0.28 \pm 4.84$ & $0.54 I^{b}$ \\
\hline \multicolumn{7}{|l|}{ Anxiety score } \\
\hline Pretest & $35.49 \pm 9.68$ & & $32.83 \pm 7.91$ & & $34.16 \pm 8.88$ & $0.177^{b}$ \\
\hline Posttest & $34.12 \pm 10.54$ & & $27.9 \pm 6.52$ & & $31.01 \pm 9.25$ & $0.002^{\mathrm{b}, * *}$ \\
\hline Changes & $-1.37 \pm 7.33$ & $0.240^{\mathrm{a}}$ & $-4.93 \pm 6.73$ & $0.000^{\mathrm{a}, * * * *}$ & $-3.15 \pm 7.22$ & $0.025^{\mathrm{b}, *}$ \\
\hline
\end{tabular}

Notes: $* P<0.5, * * P<0.01$, and $* * * P<0.001$. aPaired $t$-test. 'Independent $t$-test.

Abbreviations: $M$, mean; SD, standard deviation.

In contrast, the postbiopsy diastolic blood pressure in the experimental group significantly decreased compared to the prebiopsy level (Table 4). Taken together, these indicated that except for diastolic blood pressure, intervention measures had no significant effects on the breathing rate, heart rate, and systolic pressure of the experimental group.

\section{Discussion}

The TRUS biopsy of the prostate is a procedure requiring admission and local anesthesia in our hospital, and it is a very stressful procedure for patients. In this study, prebiopsy one-by-one simulation education was combined music therapy during biopsy to relieve the pain and anxiety of patients undergoing TRUS biopsy of the prostate. The patients suffered from mild pain (mean VAS score, 2.94) after the procedure, and this was higher than the results of the study by Tsivian et al (mean VAS score, 1.84). ${ }^{5}$ This may be due to the different methods of relieving pain and the different pain perceptions. In this study, before initiating the procedure, we also applied lidocaine jelly on the anus.

Table 4 Generalized estimating equation (GEE)

\begin{tabular}{|c|c|c|c|c|c|c|c|c|c|c|c|c|}
\hline \multirow[t]{2}{*}{ Parameters } & \multicolumn{2}{|l|}{ Pain } & \multicolumn{2}{|l|}{ Anxiety } & \multicolumn{2}{|l|}{$\begin{array}{l}\text { Systolic } \\
\text { pressure }\end{array}$} & \multicolumn{2}{|l|}{$\begin{array}{l}\text { Diastolic } \\
\text { pressure }\end{array}$} & \multicolumn{2}{|l|}{ Heart rate } & \multicolumn{2}{|c|}{ Breathing rate } \\
\hline & Estimate & SE & Estimate & SE & Estimate & SE & Estimate & SE & Estimate & SE & Estimate & SE \\
\hline Intercept & $0.46 * * *$ & 0.12 & $35.49 * * *$ & 1.49 & 133.88 *** & 2.48 & $79.05 * * *$ & 1.58 & $78.93 * * *$ & 1.37 & $18.98 * * *$ & 0.24 \\
\hline \multicolumn{13}{|l|}{ Control time } \\
\hline Posttest vs pretest & $2.95 * * *$ & 0.38 & -1.37 & 1.13 & $|9.5| * *$ & 3.55 & $19.39 * * *$ & 3.14 & $-5.00 * *$ & 1.87 & 0.61 & 0.81 \\
\hline \multicolumn{13}{|l|}{ Control group } \\
\hline Experiment vs control & $0.7 I^{* * *}$ & 0.22 & -2.66 & 1.93 & 0.83 & 3.54 & 1.12 & 2.50 & -4.15 & 2.35 & -0.1 & 0.35 \\
\hline \multicolumn{13}{|l|}{ Interaction } \\
\hline Experiment $\times$ posttest & $-1.63 * *$ & 0.55 & $-3.56^{*}$ & 1.54 & -8.73 & 5.84 & $-9.05^{*}$ & 4.37 & -0.44 & 3.30 & -0.66 & 1.06 \\
\hline
\end{tabular}

Notes: $* p<0.05, * * p<0.01$, $* * * p<0.001$.

Abbreviation: SE, standard error. 
However, this study added intravenous pethidine, whereas Tsivian et al added local injection of $1 \%$ lidocaine. This difference requires further evaluation. In addition, the prebiopsy baseline VAS scores were higher in the experimental group than in the control group. We supposed that patients with higher baseline pain VAS score will increase higher after biopsy of prostate. But for experimental group, the amplitude of decreasing VAS score is still higher than the control group. Therefore, if the baseline pain score is similar in both groups then the difference will be more significant. Many studies ${ }^{5,6}$ recommended music therapy for relieving pain after surgery or invasive medical procedure. However, there is no consensus about the effect of education (favor: LaMontagne et al and Hsiang et al; oppose: Doering et al).$^{7-9}$ The present study reveals that the combination of music therapy and one-by-one simulation education can reduce pain for patients undergoing TRUS biopsy of the prostate. Nonetheless, the working mechanism warrants further evaluation.

Previous studies reveal that music therapy has significant effects on reducing SAI score in patients undergoing less invasive procedures such as cystoscopy under local anesthesia. ${ }^{7,13,14}$ However, other studies report that music therapy has no significant effects on decreasing SAI score. ${ }^{15,16}$ The possible explanation is that more invasive procedures (such as cesarean section or coronary angiography) may lessen the effectiveness of music therapy. ${ }^{17}$ In the current study, the duration of music therapy is 20 minutes, shorter than in other studies. ${ }^{6,15}$ The patients have a SAI score of 34.16 before the TRUS biopsy, representing mild anxiety. In contrast, Tsivian et al reported 47.3 points, representing moderate anxiety. ${ }^{5}$ In addition, Tsivian et al noted no apparent better effects in the use of noise-canceling headphones than those without, whereas the patients in this study used headphones. ${ }^{5}$ It remains to be determined if ethnicity or race is a major main cause of different anxiety.

Tsivian et al reported no significant reduction in systolic and diastolic blood pressure, respiratory rate, and heart rate after TRUS-guided biopsy in the music therapy group. ${ }^{5}$ However, postbiopsy diastolic blood pressure remained stable in the music therapy group $(P=0.552) .{ }^{5}$ In this study, the reduction in respiratory rate, heart rate, and systolic pressure in patients given stress management was not significant. The change of diastolic pressure is a more reliable physiologic parameter associated with pain and anxiety. ${ }^{5}$ In this study, the diastolic pressure significantly decreased after biopsy in patients who received stress management. Thus, music therapy combined with one-on-one simulation education is more effective in improving a patient's physiologic profile than music therapy alone. Anxiety increases pain perception through the activation of the adrenergic response and simulation education before biopsy can reduce this anxiety.

The advantages of stress management include a clear understanding of the entry procedures and surgical process by the patient, increased familiarity with the surgical environment and personnel involved, increased patient satisfaction regarding the entire procedure, reduction of anxiety and pain, and a shift in the patient's attention during the procedure via music. The shortcomings of stress management may be time-consuming, and more human resources are also required. The limitations of this study are that we do not use other therapies such as relaxing therapy or hypnotherapy for comparison, and another control group with patients under noninvasive procedure will be better. Therefore, further studies will be needed.

\section{Conclusion}

In conclusion, stress management such as combined musical therapy and one-on-one simulation education may decrease the pain and anxiety of patients undergoing TRUS biopsy of the prostate under local anesthesia.

\section{Acknowledgments}

The authors thank Dr Thomas Y Hsueh and Dr Andy C Huang for their assistance.

\section{Disclosure}

The authors report no conflicts of interest in this work.

\section{References}

1. Macefield RC, Metcalfe C, Lane JA, et al; ProtecT Study Group. Impact of prostate cancer testing: an evaluation of the emotional consequences of a negative biopsy result. Br J Cancer. 2010;102:1335-1340.

2. Buckley MRE, Bryant NJ, Brown JA, Tiwari P, Cooperberg PL, Wong AD. Tolerance of local anesthetic for trans-rectal ultrasound-guided prostate biopsy: our experience and a literature review. Can Assoc Radiol J. 2006;57:169-174.

3. Raber M, Scattoni V, Roscigno M, et al. Topical prilocaine-lidocaine cream combined with peripheral nerve block improves pain control in prostatic biopsy: results from a prospective randomized trial. Eur Urol. 2008;53:967-973.

4. Rodríguez-Patrón RR, Mayayo DT, Lennie ZA, González GA, Peral AM. Complications of prostatic echo-guided trans-rectal biopsy and tolerance depending on the patient and the operator. Study of 205 patients. Arch Esp Urol. 2002;55:509-521.

5. Tsivian M, Qi P, Kimura M, et al. The effect of noise-cancelling headphones or music on pain perception and anxiety in men undergoing trans-rectal prostate biopsy. Urology. 2012;79:32-36.

6. Yeo JK, Cho DY, Oh MM, Park SS, Park MG. Listening to music during cystoscopy decreases anxiety, pain, and dissatisfaction in patients: a pilot randomized controlled trial. J Endourol. 2013;27:459-462.

7. Doering S, Katzlberger F, Rumpold G, et al. Videotape preparation of patients before hip replacement surgery reduces stress. Psychosom Med. 2000;62:365-373.

8. LaMontagne LL, Hepworth JT, Cohen F, Salisbury MH. Cognitivebehavioral intervention effects on adolescents' anxiety and pain following spinal fusion surgery. Nurs Res. 2003;52:183-190. 
9. Hsiang CY, Lai YH, Wu CH, Chen ML, Huang TW. The effects of education in decreasing anxiety and postoperative pain in women with early-stage breast cancer. New Taipei J Nurs. 2001;3:91-102.

10. Chung YC, Lu SF. Implementing an intervention strategy for education to alleviate pre-operative anxiety and increase nursing satisfaction associated with laparotomy. New Taipei J Nurs. 2004;6:63-72.

11. Watkins GR. Music therapy: proposed physiological mechanisms and clinical implications. Clin Nurse Spec. 1997;112:43-50.

12. O'Callaghan CC. Complementary therapies in terminal care: pain, music creativity and music therapy in palliative care. Am J Hosp Palliat Care. 1996;13:43-49.

13. Lee D, Henderson A, Shum D. The effect of music pre-procedure anxiety in Hong Kong Chinese day patient. J Clin Nurs. 2004;13:297-303.
14. Mok E, Wong KY. Effects of music on patient anxiety. AORN J. 2003;77:396-410.

15. Amin E, Masood M. The effect of patient-selected music on early postoperative pain, anxiety, and hemodynamic profile in cesarean section. J Altern Complement Med. 2008;14:827-831.

16. Bally K, Campell D, Chesnic K, Tranmer JE. Effects of patient-controlled music therapy during coronary angiography on procedural pain and anxiety distress syndrome. Crit Care Nurse. 2003;23:50-58.

17. Evans D. The effectiveness of music as an intervention for hospital patients: a systematic review. J Adv Nurs. 2002;37:8-18.

Patient Preference and Adherence

Dovepress

\section{Publish your work in this journal}

Patient Preference and Adherence is an international, peer-reviewed, open access journal that focuses on the growing importance of patient preference and adherence throughout the therapeutic continuum. Patient satisfaction, acceptability, quality of life, compliance, persistence and their role in developing new therapeutic modalities and compounds to optimize clinical outcomes for existing disease states are major areas of interest for the journal. This journal has been accepted for indexing on PubMed Central The manuscript management system is completely online and includes a very quick and fair peer-review system, which is all easy to use. Visit http://www dovepress.com/testimonials.php to read real quotes from published authors.

Submit your manuscript here: http://www.dovepress.com/patient-preference-and-adherence-journal 